\title{
Modeling and Simulation of Gas Liquid Absorption Column for So2 Removal Process
}

\author{
V. Priya, Dhanasekar J , G.Vasumathi
}

\begin{abstract}
During coal combustion, sulphur in the coal is converted into sulphur dioxide (SO2).This sulphur dioxide (SO2) is responsible for the formation of acid rain which is one of the widespread forms of pollution all over the world that causes harmful effects to humans and environment. To minimize the adverse impacts of $\mathrm{SO} 2$, it must be removed from flue gas. For reduction of SO2, flue gas desulphurization (FGD) is most commonly used. The mathematical viewer is developed and simulated for a gas liquid absorption column to control the flow rate of H2O2.The model equation is developed by considering material balance around the column. The absorption rate is determined by using different concentration of sulphur dioxide with hydrogen peroxide. Hydrogen peroxide, not only absorbs the SO2 but it also produce useful by-product in the form of sulphuric acid (H2SO4).
\end{abstract}

Keywords: Air pollution, Flue gas, Sulphur dioxide, Desulphurization.

\section{INTRODUCTION}

$\mathrm{SO} 2$ is a vapid gas with a sharp smell delivered from the consuming of coal High convergences of SO2 can effectsly affect wellbeing, however increasingly significant today is its universal danger to general wellbeing and nature. Long-go transport of sulfuric mixes additionally prompts the testimony of sulfur in soils and conduits in areas far off from the wellspring of discharges. Sulfur affidavit, all the more generally known as corrosive downpour, adds to fermentation of timberlands and lakes. [1],[3],[5]

\section{A. PREVENTION METHODS}

Emanation of unsafe mixes to the air brought about by ignition of non-renewable energy sources is a natural concern everywhere throughout the world. Sulfur and nitrogen oxides are among the most disturbing poisons because of their extraordinary worldwide outflow and long range transport in the air.

(FGD)

Pipe (FGD) is an advancement used to empty sulfur dioxide (SO2) from the exhaust vent gases of oil subordinate power plants, and substance producers of sulfur oxides. As stringent normal rules with respect to $\mathrm{SO} 2$ spreads have been requested in various countries, $\mathrm{SO} 2$ is directly being removed from vent

\section{Revised Manuscript Received on August 22, 2019}

V.Priya, Department of Mechatronics ,Bharath Institute of Higher Education \& Research,TamilNAdu Email: priyaygna14@gmail.com

J.Dhanasekar,, Department of Mechatronics ,Bharath Institute of Higher Education \& Research,TamilNAdu Email: Jdhanasekar81@gmail.com

G.Vasumathi Department of Mechatronics ,Bharath Institute of Higher Education \& Research,TamilNAdu Email: vasu.bala06@gmail.com job as an antecedent to the development of particulates, a

gases by a grouping of procedures. The underneath is among the ordinary systems used: [7],[9], [10]

\section{Dry sorbent implantation systems.}

For a regular coal-ended power station, FGD will clear 95 percent or a more noteworthy measure of the $\mathrm{SO} 2$ in the pipe gases

\section{GAS LIQUID ABSORPTION COLUMN}

By means of gas liquid interface gaseous component is transformed from gas phase to liquid phase.

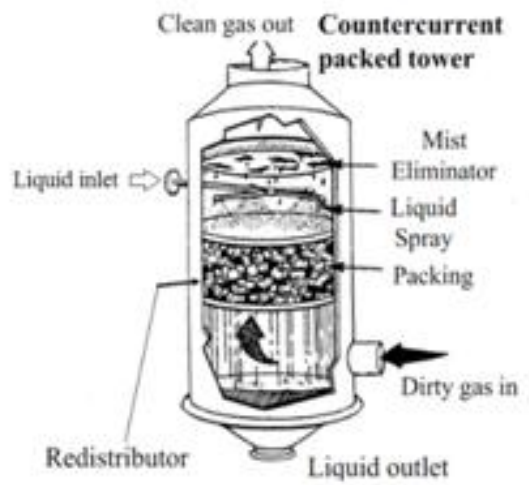

Fig.1 Counter current packed tower

\section{DEVELOPMENT OF MATHEMATICAL MODEL}

The enduring state process ingestion of the $\mathrm{CO} 2-\mathrm{NaOH}$ framework has been examined already [1] where the pace of assimilation, the pace of exchange of material through the gas film will be equivalent to that through the fluid film, and the age for the age for mass exchange of a part is portrayed by condition (1)

Material balance around the column:

$$
G\left(C_{G 1}-C_{G 2}(t)=L\left(C_{L 1}(t)-C_{L 2}(t)\right)\right.
$$

Material balance around the tank:

Inlet flow rate - outlet flow rate $=$ rate of accumulation

Schematic Gas Liquid Absorption System 


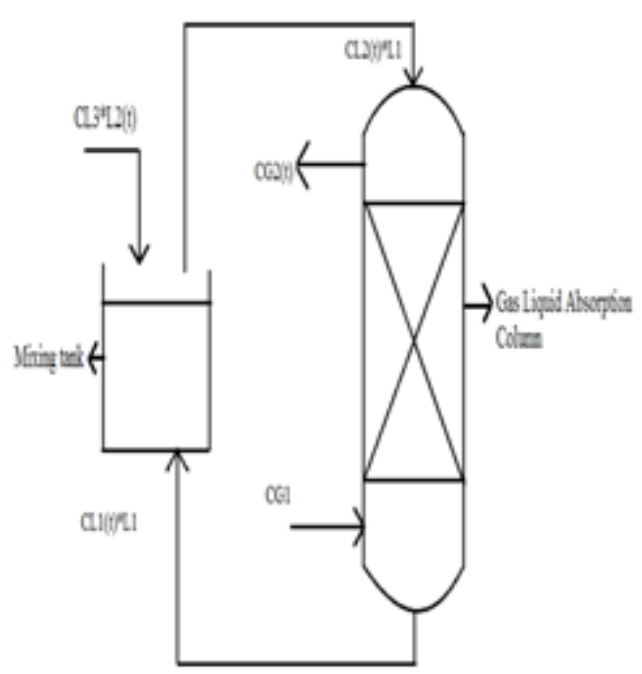

Henry's Law

Fig2.Gas Liquid Absorption System

An equivalent way of stating the law is that the solubility of a gas in a liquid is directly proportional to the Concentration of inlet gas.

$$
C L_{1}(t)=\frac{C G_{1}}{H^{r}}
$$

$C L_{1}(t)=$ Mole fraction of solute in the liquid

$C G_{1} \quad$ = Concentration of inlet gas

$H^{\gamma}=$ Henry's law constant

\section{Mixing Tank Equation}

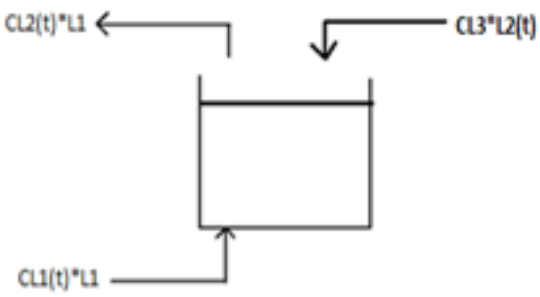

Fig 3. Mixing Tank

$$
\begin{aligned}
& \frac{V d C L_{2}(t)}{d t}=L_{1} C L_{1}(t)+C L_{3} L_{2}(t)-L_{1} C L_{2}(t) \\
& \frac{V d C L_{2}(t)}{d t}=L_{1} C L_{1}(t)-L_{1} C L_{2}(t)+C L_{3} L_{2}(t) \\
& \frac{V d C L_{2}(t)}{d t}=\left(L_{1}\left(C L_{1}(t)-C L_{2}(t)\right)+C L_{3} L_{2}(t)\right. \\
& \frac{d C L_{2}(t)}{d t}=\frac{\left(L_{1}\left(C L_{1}(t)-C L_{2}(t)\right)+C L_{3} L_{2}(t)\right.}{V} \\
& C L_{2}(t)=\int \frac{L_{1}\left(C L_{1}(t)-C L_{2}(t)+C L_{3} L_{2}(t)\right.}{V}
\end{aligned}
$$

\section{Material balance equation}

$$
\begin{aligned}
& G\left(C G_{2}(t)-C G_{1}\right)=L\left(C L_{1}(t)-C L_{2}(t)\right) \\
& C G_{2}(t)-C G_{1}=\frac{L}{G}\left(C L_{1}(t)-C L_{2}(t)(5)\right.
\end{aligned}
$$

Simulink block for Mixing Tank Equation

Function CL_2 = fcn(CL1,CL2,L2)

$\mathrm{L} 1=0.2$;

$\mathrm{V}=50$;

CL3=0.1;

CL_2 $=((\mathrm{L} 1 *(\mathrm{CL} 1-\mathrm{CL} 2)+(\mathrm{CL} 3 * \mathrm{~L} 2) / \mathrm{V}))$;

Simulink block for Wet scrubber Equation

Function [CG2,CL_1,CL_12] = fcn(CL1,CL2,L2)

CG1 $=650$;

CL3 $=0.1$

$\mathrm{K} 1=1$;

$\mathrm{K} 2=1400$;

$\mathrm{L} 1=0.2$;

$\mathrm{G}=50$;

CG2 $=(\mathrm{CG} 1-((\mathrm{L} 1 / \mathrm{G}) *(\mathrm{CL} 1-\mathrm{CL} 2)))$

CL_1 $=$ CG1/K1;

CL_12 $=(\mathrm{CG} 1 *(\mathrm{CL} 3 / \mathrm{L} 2) * \mathrm{~K} 2)$

\section{RESULT AND DISCUSSION}

Characteristic graph:

Flow rate Vs Removal Efficiency

For different flow rates, corresponding Removal Efficiency of the acid are noted. It is realized that for expanding in the stream pace of hydrogen peroxide the Removal Efficiency of the acidobtained gets expanded. Thus reasonable stream rate is to be picked for better yield of the corrosive.



\section{Flow rate Vs Removal Efficiency}

Time Vs Outlet Concentration of $\mathrm{SO}_{2}$

When the time increase the outlet concentration of $\mathrm{SO}_{2}$ continuously decreases and after a certain period of increasing time the outlet concentration remains constant. 
Time Vs Outlet Concentration of SO2



Fig.5 Time Vs Outlet concentration of $\mathrm{SO}_{2}$

\section{CONCLUSIONS}

From reproduction work it is affirmed that, (SO2) is changed over to sulfuric corrosive by utilizing Hydrogen peroxide ( $\mathrm{H} 2 \mathrm{O} 2)$.By fluctuating stream pace of $\mathrm{H} 2 \mathrm{O} 2$ and furthermore by differing the centralization of SO2. From simulation it is concluded that the setting time period is increased by increasing the inlet concentration of SO2.The modelling approach used, provides the better performance result. [2 ]$,[4],[6]$

\section{REFERENCES}

1. Dhanasekar, J., Sengottuvel, P. \& Palanikumar, K. 2019, "Implementation of effective fuel saving methodology for turbines using air drag in vehicles", Materials Today: Proceedings, pp. 421

2. Kumar, S.S., Kumar, K.S.R. \& Kumar, N. 2018, "Experimental evaluation of magnetorheological damper characteristics for vibration analysis", International Journal of Vehicle Structures and Systems, vol. 10, no. 1, pp. 30-34.

3. Dhamodaran, K., Adikesavana, P., Shankar, P.P. \& Gowtham, S. 2018, "Conceptual development of flapping wing for unmanned aerial vehicles: Technical note", International Journal of Vehicle Structures and Systems, vol. 10, no. 1, pp. 43-45.

4. Karthikeyan, S., Raman Balasubramanian, S.R., Ramesh, B., Raghul, S. \& Sathish Kumar, S. 2019, "The automatic solar tracker chronicles", International Journal of Recent Technology and Engineering, vol. 8, no. 1, pp. 312-315.

5. Hema, R., Sundararajan, M. \& Balaji, S. 2019, "Smartphone control robot with automatic firing gun", International Journal of Innovative Technology and Exploring Engineering, vol. 8, no. 9 Special Issue 3 , pp. 625-627.

6. Balambica, V., Deepak, V. \& Kumar, S. 2019, "Design and efficiency of an asymmetric gear", International Journal of Mechanical and Production Engineering Research and Development, vol. 9, no. 3, pp. 223-230.

7. Saravana, S., Balaji, S., Arulselvi, S. \& John Paul Praveen, A. 2019, "Reliable power quality monitoring and protection system", International Journal of Innovative Technology and Exploring Engineering, vol. 8, no. 9 Special Issue 3, pp. 644-645.

8. Bycil, V.J. \& Wiselin, M.C.J. 2019, "Modeling and analysis of vibration energy harvesting system using piezo stack", International Journal of Mechanical and Production Engineering Research and Development, vol. 9, no. Special Issue 1, pp. 523-533.

9. Sripada, A., Warrier, A., Kapoor, A., Gaur, H. \& Hemalatha, B. 2018, "Dynamic lateral balance of humanoid robots on unstable surfaces", International Conference on Electrical, Electronics, Communication Computer Technologies and Optimization Techniques, ICEECCOT 2017, pp. 539.

10. Mahalakshmi, V. \& Vijayaragavan, S.P. 2019, "PV based power electronic converters for high voltage DC applications", International Journal of Recent Technology and Engineering, vol. 7, no. 6, pp. 670-674.

\section{AUTHORS PROFILE}

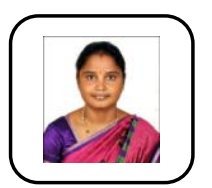

Priya V Assistant Professor,Department of Mechatronics Bharath Institute of Higher Education \& Research,TamilNAdu

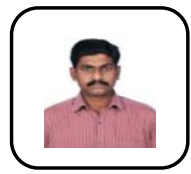

Dhanasekar. J,

Assistant Professor,Department of Mechatronics Bharath Institute of Higher Education \& Research,TamilNAdu

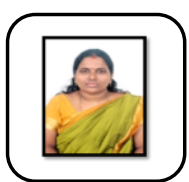

Vasumathi. Assistant, Professor,Department of Mechatronics Bharath Institute of Higher Education \& Research,TamilNAdu 